Ambient Science, 2018: Vol. 05(Sp2); 51-55

DOI:10.21276/ambi.2018.05.sp2.aa01

ambient

SCIENCE

Published by: National Cave Research and Protection Organization, India

Vol. 5(Sp2):51-55

Year 2018

AMBIENT APPRAISAL

\title{
Arsenic Contamination in the Groundwater and Soil of Trans Indo- Gangetic Plain (TIGP) of India \\ Abstract
}

\section{Hema Singh*, Sangeeta Goomer}

Lady Irwin College, Sikandra Road, Delhi-11ooo1

Study Area: Punjab, Haryana, Delhi of India

Coordinates: $30.79^{\circ} \mathrm{N} ; 75.84^{\circ} \mathrm{E}, 30^{\circ} 44^{\prime} \mathrm{N} ; 76^{\circ} 47^{\prime} \mathrm{E}$

$\& 28^{\circ} 36^{\prime} 36^{\prime \prime} \mathrm{N} ; 77^{\circ} 13^{\prime} 48^{\prime \prime} \mathrm{E}$

Key words: Tube-well Water, Paddy Soil, Poison level, Toxicity level

\section{Introduction:}

Arsenic (As) is a toxic metalloid, also termed as "poison" among the general public. It could be found in water, soil, air and in all living organisms. It exists in organic or inorganic forms, where inorganic forms are generally considered more toxic (Zhao et al., 2010). Epidemiological studies showed that the chronic arsenic poisoning has caused serious health effects on humans including cancers, diabetes mellitus, gangrene, hypertension, hyperkeratosis, ischemic heart disease, melanosis, restrictive lung disease and peripheral vascular disease (Maity et al., 2012). Worldwide over 200 million populations have been affected with the arsenic contaminated groundwater at the concentration greater than the World Health Organization safe limit $\left(10 \mu \mathrm{g} \mathrm{As} \mathrm{L}^{-1}\right)$ in 105 countries of the world (WHO, 2011; Murcott, 2012; Naujokas et al., 2013). India is a monsoon-dependent country where groundwater is the dominant source for irrigation of crops, constituting over $80 \%$ of the groundwater for irrigation purposes in the IndoGangetic Plain (IGP) of India (Patil et al., 2014). Available reports suggested that groundwater of IGP region is highly contaminated with arsenic (As) levels (up to $500 \mu \mathrm{g} \mathrm{L}^{-1}$ ) under Ganga-Meghna-Brahmaputra basin (GMB)
The present study was aimed at assessing the concentration of Arsenic (As) in groundwater and paddy soil of the Trans Indo-Gangetic Plain (TIGP) of India. Total arsenic in groundwater and soil was determined by Inductively Coupled Plasma-Mass Spectrometry (ICP-MS), and Inductively Coupled Plasma-Atomic Emission Spectroscopy (ICP-AES), respectively. The results revealed that approximately, $33 \%$ of the groundwater samples had arsenic (As) concentrations greater than the maximum permissible limit (10 $\mu \mathrm{g}$ As $\mathrm{L}^{-1}$ ) set by the World Health Organization (WHO). In paddy soil samples, $33 \%$ of the samples had As concentrations greater than the maximum acceptable limit for agricultural soil (20 mg As $\mathrm{kg}^{-1}$ ) recommended by the European Community (EC). Arsenic concentration in groundwater was significantly and moderately correlated with As concentrations in paddy soil in TIGP region. Thus, groundwater and paddy soil of TIGP region can be the potential source of As in the paddy crops grown on these fields. Proper mitigation steps should be implemented in those regions where As concentrations in groundwater and soil of TIGP are higher than the safe limit.

(Bhattacharya et al., 2007). Several other states in IGP region have been identified as arsenic contaminated states with arsenic levels far exceeding the WHO guideline value $\left(10 \mu \mathrm{L} \mathrm{L}^{-1}\right)$ and the Bureau of India Standard (BIS) $\left(50 \mu \mathrm{g} \mathrm{L}^{-1}\right)$ of arsenic in drinking water. According to UNICEF survey in 2005, the groundwater which has been found unsafe for drinking purposes is still being used continuously for irrigating agricultural fields in the IGP region (Srivastava et al., 2015). Previous studies have indicated that when fields were irrigated with arsenic contaminated groundwater, it elevated the concentrations of arsenic in the upper layers of soil as well as in the crops which were grown on these soils (Rahman et al., 2008; Bhattacharya et al., 2010). The soil environment is known to act as a major sink to arsenic (Sanyal \& Nasar, 2002). Arsenic rapidly accumulates into the soil as it depletes only through erosion, methylation, leaching or plant uptake (Fergusson, 1990). Interestingly, among all the crops, rice crops are the most susceptible crops that accumulate greater arsenic concentration from the fields. They are cultivated under flooded conditions of irrigation land, which makes soil environment reduced in condition that facilitates arsenic mobilization in the rice fields ( Roberts et al., 2011; Spanu et al., 2012). This is a

*Corresponding Author: hema.singhı3@yahoo.in 
matter of concern as rice is a staple crop across the country, which if contaminated with arsenic will cause greater arsenic exposure in humans. Studies on As concentration in groundwater and soil have been conducted extensively in the Lower Indo-Gangetic Plain of India, i.e., West Bengal (Chakraborti et al., 2009; Das et al., 2009; Rahman et al., 2014). However, we have very bleak information on As distribution in the groundwater and paddy soil of Punjab, Haryana, and Delhi, collectively called as Trans IndoGangetic Plain (TIGP) of India. Thus, the present investigation aimed to study the As concentrations in groundwater and paddy soil of TIGP region of India. We also examined the relationship between the As concentrations in groundwater used for irrigation and the surface soil of irrigated paddy field around tube well.

\section{Methodology:}

Study area: the study was conducted in total six different administrative districts belongs to three different states: Punjab, Haryana, and Delhi, located in the Trans IndoGangetic Plain (TIGP) of Northern India. Amritsar, Jalandhar and Ludhiana districts from Punjab; Sonipat and Panipat districts from Haryana, and North-West district from Delhi were selected for sampling purposes. In each district, two villages were selected and from each village two tube-well operated paddy fields were selected for collection of samples. To avoid arsenic contamination from any other source of irrigation water, only those fields were selected where tube well water was the only source of irrigation. In total, 24 field sites were selected for the collection of the TW water and soil samples.

\section{Sample collection and preparation:}

Groundwater: tube-well (TW) water samples $(500 \mathrm{ml})$ were collected from tube well pumps used for the irrigation of paddy fields in November 2016 (Hundal et al., 2009). In total, 24 TW water samples were collected from TIGP region. Water samples were collected in polyethylene bottles, pre-washed with $1 \%$ nitric acid and dried prior to their use. The pumps were kept running for about 10-15 min in order to get a uniform rate of discharging water. Before collecting the samples, bottles were rinsed three to five times with the water sample to be taken. Immediately after the collection of each sample, nitric acid (o.1\% v/v) was added to each bottle for preservation (Uchino et al., 2006). All water samples were filtered through Whatman filter paper no. 42 and stored at $4^{\circ} \mathrm{C}$ prior to analysis (Bhattacharya et al., 2010; Rahaman et al., 2013).

Soil Samples: soil samples (50o g) were collected in November 2016 covering the same sites from where TW water samples were collected. Soil surface samples $(0-15 \mathrm{~cm})$ were collected from 4-5 random points ( $2 \mathrm{~m}^{2}$ area) of paddy fields and then merged to a single representative composite sample of a field and then transferred to airtight polyethylene bag. The soil samples were then immediately sun-dried and later dried in the hot air oven at $60^{\circ} \mathrm{C}$ for 72 hrs. The dried soil samples were ground by cautiously disaggregating in a mortar and screened through 2.0-mm pore sized sieve to get homogenized representative powder sample. Finally, the samples were stored in airtight polyethylene bags at room temperature for analysis (Bhattacharya et al., 2010; Sidhu et al., 2012; Rahaman et al., 2013).

Determination of Arsenic: to determine Arsenic in water samples, $10 \mathrm{ml}$ aliquots of each sample were taken into test tubes. All acid washed glassware $\left(2 \% \mathrm{HNO}_{3}\right)$ were rinsed with de-ionized water and dried. Total As in water samples were analyzed on an Inductively Coupled Plasma - Mass Spectrometry (ICP-MS) at the Sophisticated Analytical Instrument Facility (SAIF) in IIT Bombay, India. Soil subsamples were weighed (o.1-0.2 g) into PFA vessels, digested using nitric acid-hydrofluoric acid procedure. The Multiwave-300o microwave reaction system (Anton Paar) was used for sample preparation. Samples were added in each of the PFA vessels, and then $5 \mathrm{ml}$ nitric acid (Merck, Analytical grade) and $2 \mathrm{ml}$ hydrofluoric acid (Merck, Analytical grade) were added. The decomposition time duration was 50 min and for cooling, time duration was 20 min. The mean temperature reached was $228^{\circ} \mathrm{C}$ (max power: $800 \mathrm{~W}$, max pressure: 60 bar). The mostly clear decomposed sample solutions were made up to $25 \mathrm{ml}$ in 50 $\mathrm{ml}$ plastic vials. Total As in the samples was analyzed using ICP-AES (SPECTRO Analytical Instrument $\mathrm{GmbH}$, Germany) at the Sophisticated Analytical Instrument Facility (SAIF) in IIT Bombay, India.

Validation of the method to check accuracy: Certipur Certified Reference material (As) 100 ppm-certified value (traceable to SRM from NIST SRM 3103a) LOT HC 56697894 purchased from Merck company was used to validate the analytical method. The As concentration standard used for each calibration was also prepared fresh for each run. Calibration curves were rerun if the measured value were not within $5 \%$ expected value. Laboratory control check standards were run after every 8 and 15 samples in ICP-MS and ICP-AES, respectively. Mean total recovery of As from the NIST standard were $98.4 \pm 0.8(\mathrm{n}=5)$ and $99.4 \pm 1.4 \%$ $(\mathrm{n}=5)$ with LOD: $0.0214 \mu \mathrm{g} \mathrm{As} \mathrm{L^{-1 }}$ and $0.006 \mu \mathrm{g} \mathrm{As} \mathrm{L}{ }^{-1}$ of ICPMS and ICP-AES, respectively.

Statistical analysis: the independent t-test and correlation coefficients were calculated using SPSS zo.o.

\section{Results and Discussion:}

The mean ( \pm standard error) of As concentrations gathered from TW water samples collected from 12 villages of TIGP region of India is presented in Fig.-1. The As concentrations of the water samples $(n=24)$ ranged from 1.76 to $64.07 \mu \mathrm{g}$ As

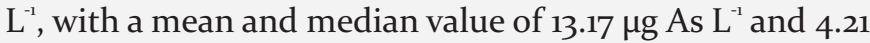
$\mu g$ As $L^{-1}$, respectively. The present study showed that the mean value of total As present in groundwater of TIGP region was greater than the $\mathrm{WHO}$ potentially toxic limit 
(10.0 $\mu \mathrm{g} \mathrm{As} \mathrm{L}^{-1}$ ). However, this value was much lower when compared with the BIS limit ( $50 \mu \mathrm{g}$ As $\left.\mathrm{L}^{-1}\right)$. Our results showed that about $33 \%$ of groundwater samples had As concentrations greater than the WHO (2011) limit, and only about $4 \%$ of water samples had As concentrations greater than the BIS limit. The concentrations of As varied, with

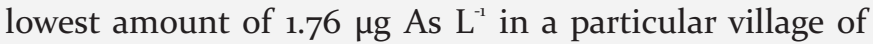
Ludhiana district and the greatest amount of $64.07 \mu \mathrm{g} \mathrm{As} \mathrm{L^{-1 }}$ in an another village of Amritsar district. The total As concentration in TW water samples of Punjab, Haryana,

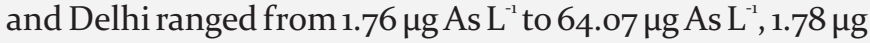
As $L^{-1}$ to $43.68 \mu \mathrm{g}$ As $L^{-1}$ and $2.21 \mu \mathrm{g}$ As $\mathrm{L}^{-1}$ to $25 \mu \mathrm{g}$ As $\mathrm{L}^{-1}$, respectively. No significant difference was observed in the concentration of As of groundwater samples between these three states (Fig.-1). Sidhu et al., (2012) reported 9.21 \pm 3.24 $\mu \mathrm{g} \mathrm{As} \mathrm{L^{-1 }}$ (mean $\pm \mathrm{SD}$ ) arsenic in groundwater of Punjab, which was lower when compared with the present data. In Haryana, based on a survey conducted in 2008 , As in

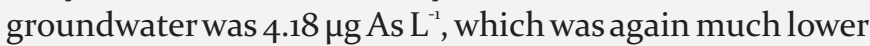
when compared with the present study. Higher concentrations of As in TW water of Punjab and Haryana probably indicate the dominance of natural rather than anthropogenic sources such as an application of Ascontaining chemicals in the agricultural crops (Sidhu, 2007; Roy et al., 2008). From Delhi, As concentration in TW water we obtained was lower as compared to the studies conducted by Lalwani et al., (2004). The analytical method used may also lead to variation in the levels obtained due to the sensitivity of individual method (Roy et al., 2008).

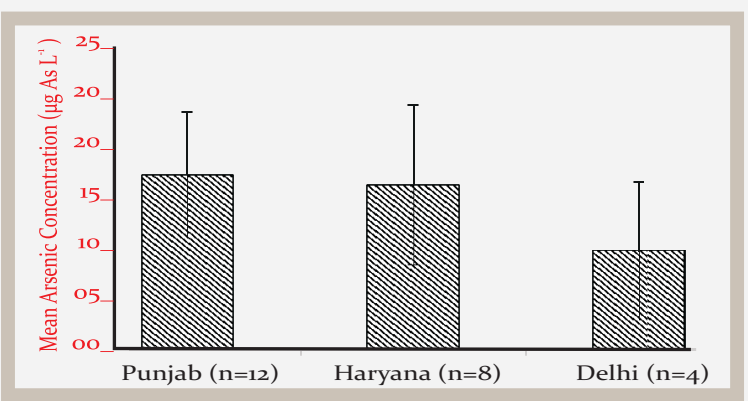

Figure-1: Mean Arsenic levels obtained from tubewell (TW) of water samples collected from the three states of TIGP region

Total arsenic (As) concentration in soil: the total As varied greatly from, $1.27 \mathrm{mg}$ As $\mathrm{Kg}^{-1}$ to $81.46 \mathrm{mg}$ As $\mathrm{Kg}^{-1}$ dry weight ( $\mathrm{dw}$ ). The range of As concentration in the present study was wider, due to the contribution of one soil sample

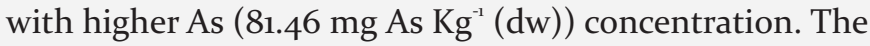

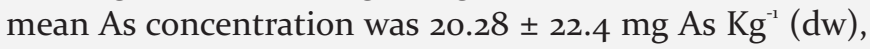
with a median value of $10.18 \mathrm{mg} \mathrm{As} \mathrm{Kg}^{-1}(\mathrm{dw})$. The mean value of the present study was found to be slightly higher when compared with the maximum acceptable limit for agricultural soil (20 $\mathrm{mg} A s \mathrm{Kg}^{-1}$ ) recommended by the European Community (EC) (O'Neil, 1995). Our results showed that about $33 \%$ of the soil samples had As concentrations greater than the acceptable limit. Singh et al., (2010) studied the arsenic concentration in paddy soil in the Indo-Gangetic Plains of Northwestern India. They reported that As concentration varied from 1.09 to $2.08 \mathrm{mg}$ As Kg-1, which was much lower when compared with the present data. Similarly, the As concentrations in soil samples of the present study was higher when compared with most of the published data, except Chhattisgarh (mean $61 \mathrm{mg} \mathrm{As} \mathrm{Kg}^{-1}$ ), West Bengal (mean $38.2 \mathrm{mg} \mathrm{As} \mathrm{Kg}^{-1}$ ) and Taiwan (mean $52.23 \mathrm{mg} \mathrm{As} \mathrm{Kg}^{-1}$ ) (Sidhu et al., 2012; Biswas et al., 2014; Ghosh et al., 2014; Rahman et al., 2010; Fu et al., 2011; Jiang et al., 2014, 2015; Bogdan \& Schenk, 2009; Kim, 2013; Hsu et al., 2012). Higher concentration of arsenic in the soil of paddy fields could be due to the long-term use of arsenic contaminated irrigation water and arsenical pesticides. However, the effect of arsenical pesticides on soil As concentrations was beyond the scope of the study.

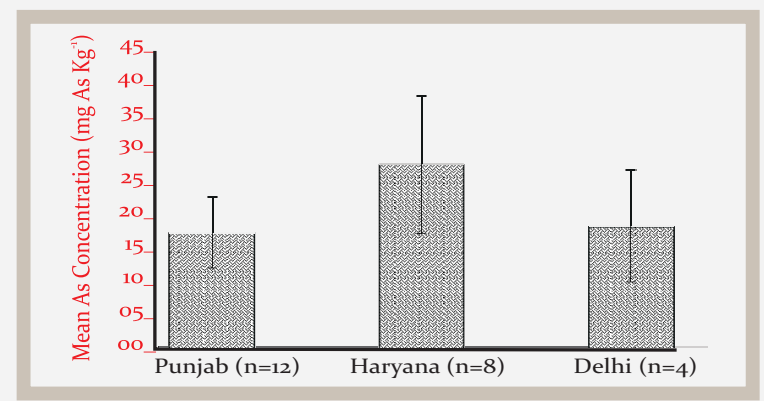

Figure-2: Mean Arsenic levels obtained from the soil samples of paddy fields collected from the three states of TIGP region

Fig.- 2 shows the the mean As concentrations in paddy soil obtained from the three states of TIGP region ranged from $1.27 \mathrm{mg}$ As kg-1 to $63.9 \mathrm{mg} \mathrm{As} \mathrm{kg}^{-1}$ (dw), $65.55 \mathrm{mg} \mathrm{As} \mathrm{kg}^{-1}$ to $81.46 \mathrm{mg} \mathrm{As} \mathrm{kg}^{-1}$ (dw) and $5.69 \mathrm{mg} \mathrm{As} \mathrm{kg}^{-1}$ to $43.51 \mathrm{mg} \mathrm{As} \mathrm{kg}^{-1}$ $(\mathrm{dw})$, respectively. We found no significant difference in the As the concentration of paddy soil between the three states. However, district-wise some major differences between the districts were evidenced. There are several factors responsible for the difference in the arsenic concentration in soil. Arsenic in soil deposits, through natural processes of weathering of As-bearing rocks or use of As-contaminated groundwater for irrigation or because of anthropogenic activities such as mining (Azcue et al., 1994), smelting (Manful, 1992), landfilling of industrial wastes, disposal of chemical warfare agents (Schneider \& Johnson, 1999), agriculture (Merwin et al., 1994), application of As pesticides, accident (Sierra et al., 200o), burning coal (Rubin, 1999), preservation of wood (Moore et al., 2000) and illegal waste dumping (Tokunaga \& Hakuta, 2002).

Correlation of Arsenic concentrations in groundwater and surface soil: in the present study, only those fields were selected which were growing paddy during Kharif season, irrigated with only TW water. Fig.-3 shows the relationship between As concentration in groundwater and paddy soil samples of Trans Indo-Gangetic Plain (TIGP) of India. A positive and moderate correlation was observed 
between the As concentration in TW water and As concentration in surface soils of the paddy field. According to Panaullah et al. (2009), approximately whole of the As added through irrigation water gets retained in the surface soil, which increases the As concentration in paddy soil. The present study results clearly indicated that the TW waters containing more As, accumulated more As in the surface soils. Therefore, buildup As in soils is directly related to the As concentration in TW water, although the number of samples was limited. These results also indicate that there is a risk associated with growing paddy in the TIGP region, as both the soils and irrigated waters are contaminated with As. Paddy crops grown on As contaminated soil, irrigated with As-contaminated water accumulates a higher concentration of arsenic as compared to other cereal crops (William et al., 2007).

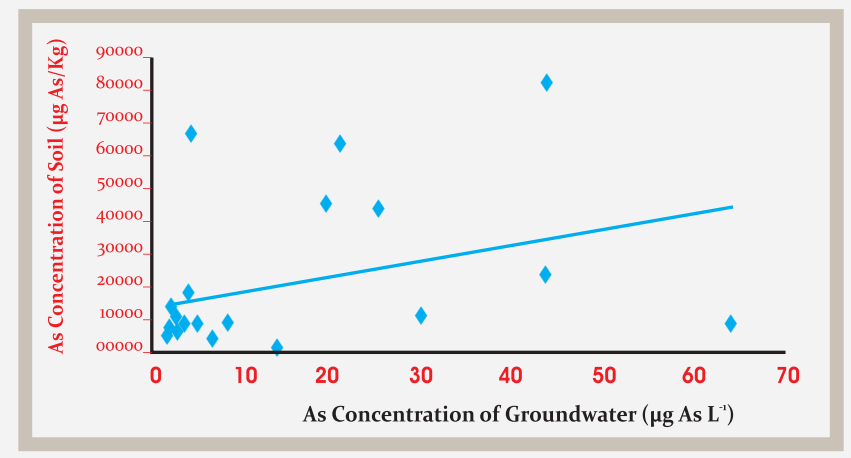

Figure-3: Relationship between As concentration in groundwater and paddy soil samples of TIGP, India

\section{Conclusion and future recommendations:}

The present study reveals the total As concentrations in the TW water and paddy soil of TIGP region of India. Arsenic was present in all water and soil samples and some of the samples also exceeded the maximum acceptable limit. This clearly indicates that water extracted by tube well in the TIGP region is contaminated with arsenic, depositing As into the soils of TIGP region, thus increasing the concentration of arsenic in the soils. Hence, groundwater of TIGP region is one of the sources of arsenic transferring into the surface soils, along with other sources like anthropogenic sources. Since paddy crops accumulate more arsenic from the irrigated water and As contaminated soil as compared to other cereal crops, there is an urgent need to address this problem. Therefore, regular monitoring and increased awareness among the policymakers and the scientific community is required to assess the harmful effects of As contamination on the environment. Proper mitigation steps should be implemented in those areas where arsenic concentration in water and soil are above the safe limit. In the future, the incidence of arsenic related health problems should also be monitored annually from the locations where the arsenic content of groundwater is above and lower the safe limits.

\section{Acknowledgements:}

The authors are cordially acknowledging the Sophisticated Analytical Instrument Facility (SAIF) Lab, IIT Bombay for giving the permission to use their ICP-MS, ICP-AES and Chemical Analysis Lab. The authors are also thankful to IARI Pusa, Delhi and Lady Irwin College, Delhi University for providing the opportunity to do research. The first author is also thankful to the University Grants Commission (UGC), for awarding the UGCNET/SRF fellowship for the research work. .

\section{References:}

Azcue, J.M., Mudroch, A., Rosa, F., \& Hall, G.E.M. (1994): Effects of abandoned gold mine tailings on the arsenic concentrations in water and sediments of Jack of Clubs Lake, BC. Environ. Technol., 15(7):669-678.

Bhattacharya, P., Samal, A.C., Majumdar, J. \& Santra, S.C. (2010): Arsenic contamination in rice, wheat, pulses, and vegetables: A study in an arsenic affected area of West Bengal, India. Water Air Soil Pollut., 213(1-4):3-13.

Bhattacharya, P., Welch, A.H., Stollenwerk, K.G., McLaughlin, M.J., Bundschuh, J. \& Panaullah, G. (2007): Arsenic in the environment: Biology and Chemistry. Sci. Total Environ., 379(2-3):109-120.

Biswas, A., Biswas, S., Santra S.C. (2014): Arsenic in irrigated water, soil, and rice: perspective of the cropping seasons. Paddy Water Environ., 12(4):407-412.

Bogdan, K. \& Schenk, M.K. (2009): Evaluation of soil characteristics potentially affecting arsenic concentration in paddy rice (Oryza sativa L.). Environ Pollut., 157(10):26172621.

Chakraborti, D., Rahman, M.M., Das, B., Murrill, M., Dey, S., Mukherjee, S.C., Dhar, R. K., Biswas, B.K., Chowdhury, U.K., Roy, S., Sorif, S., Selim, M., Rahman, M., \& Quamruzzaman, Q. (2010): Status of groundwater arsenic contamination in Bangladesh: a 14-year study report. Water Res., 44(19):57895802 .

Das, B., Rahman, M.M. Nayak, B., Pal, A., Chowdhury, U.K., Mukherjee, S.C., Saha, K.C., Pati ., S., Quamruzzaman, Q. \& Chakraborti, D. (2009): Groundwater Arsenic Contamination, Its Health Effects and Approach for Mitigation in West Bengal, India and Bangladesh. Water Qual Expo Health, 1(1):5-21.

Fergusson, J.E. (1990): The heavy elements: Chemistry, environmental impact, and health effects. Pub. by: Pergamon Press. 614 p.

Fu, Y., Chen, M., Bi, X., He, Y., Ren, L., Xiang, W., Qiao, S., Yan, S., Li, Z. \& Ma, Z. (2011): Occurrence of arsenic in brown rice and its relationship to soil properties from Hainan Island, China. Environ Pollut., 159(7):1757-1762.

Ghosh, M., Roy, P.K. \& Majumder, A. (2014): Effect of Arsenic rich soil and groundwater on paddy cultivation. World Appl. Sci.J., 29(2):165-170.

Hsu, W.M., His, H.C., Huang, Y.T., Liao, C.S., \& Hseu, Z.Y. (2012): Partitioning of arsenic in soil-crop systems irrigated using groundwater: A case study of rice paddy soils in southwestern Taiwan. Chemosphere, 86(6):606-613.

Hundal, H.S., Singh, K. \& Singh, D. (2009): Arsenic content in ground and canal waters of Punjab, North-West India. Environ Monit. Assess., 154:393-400. 
Jiang Y., Zeng X., Fan, X., Chao, S., Zhu, M. \& Cao, H. (2015): Levels of arsenic pollution in daily foodstuffs and soils and its associated human health risk in a town in Jiangsu Province, China. Ecotoxicol. Environ. Saf., 122:198-204.

Jiang, W., Hou, Q., Yang, Z., Zhong, C., Zheng, G., Yang, Z. \& Li, J. (2014): Evaluation of potential effects of soil available phosphorus on soil arsenic availability and paddy rice inorganic arsenic content. Environ. Pollut., 188:159-165.

Lalwani, S., Dogra, T.D., Bhardwaj, D.N., Sharma, R.K., Murty, O.P., \& Vij. A. (2004): Study on arsenic level in groundwater of delhi using hydride generator accessory coupled with atomic absorption spectrophotometer. Indian J. Clin. Biochem., 19(2):135-140.

Maity, J.P., Nath, B., Kar, S., Chen, C.Y., Banerjee, S., Jean, J.S., Liu, M.Y., Centenom J.A., Bhattacharya, P., Chang, C.L. \& Santra, S.C. (2012): Arsenic-induced health crisis in peri-urban Moyna and Ardebok villages, West Bengal, India: an exposure assessment study. Environ. Geochem. Health. 34(5):563-574.

Manful, G.A. (1992): Occurrence and ecochemical behavior of arsenic in a goldsmelter impacted area in Ghana. Pub. by: Universiteit Gent. 172 p.

Merwin, I., Pruyne, P.T., Ebel, J.G., Manzell, K.L. \& Lisk, D.J. (1994): Persistence, phytotoxicity, and management of arsenic, lead and mercury residues in old orchard soils of New York State. Chemosphere, 29(6):1361-1367.

Moore, T.J., Rightmire, C.M. \& Vempati, R.K. (2000): Ferrous iron treatment of soils contaminated with arsenic-containing woodpreserving solution. Soil Sediment. Contam., 9(4):375-405.

Murcott, S. (2012): Arsenic contamination in the World: an international sourcebook. Pub. by: IWA Pub. 282 p.

Naujokas, M.F., Anderson, B., Ahsan, H., Aposhian, H.V., Graziano, J., Thompson, C. \& Suk, W.A. (2013): The broad scope of health effects from chronic arsenic exposure: update on a worldwide public health problem. Environ. Health Perspect., 121(3):295-302.

O'Neill, P. (1995). Arsenic. In: Alloway, B.J., Ed., Heavy Metals in Soils. Pub. by: Blackie and Son Ltd., Glasgow, pp 105-121.

Panaullah, G.M., Alam, T., Hossain, M.B., Loeppert, R.H., Lauren, J.G., Meisner, C.A., Ahmed, Z.U. \& Duxbury, J.M. (2009): Arsenic toxicity to rice (Oryza sativa L.) in Bangladesh. Plant Soil., 317:31-39.

Patil, N.G., Tiwary, P., Bhattacharyya, T., Chandranı, P., Sarkar, D., et al. (2014): Natural resources of the Indo-Gangetic Plains: a land-use planning perspective. Current Sci., 107(9):1537-1549.

Rahaman, S., Sinha, A.C., Pati, R., \& Mukhopadhyay, D. (2013):Arsenic contamination: a potential hazard to the affected areas of West Bengal, India. Environ. Geochem. Health, 35(1):119-132.

Rahman, M.A., Hasegawa, H., Rahman, M.M., Miah, M.A.M. \& Tasmin, A. (2008): Arsenic accumulation in rice (Oryza sativa L.): Human exposure through food chain. Ecotoxicol. Environ. Safety., 69(2):317-324.

Rahman, M.M., Mondal, D., Das, B., Sengupta, M.K., Ahamed, S., Hossain, M.A., Samal, A.C., Saha, K.C., Mukherjee, S.C., Dutta, R.N. \& Chakraborti, D. (2014): Status of groundwater arsenic contamination in all 17 blocks of Nadia district in the state of West Bengal, India: A 23-year study report. J. Hydrol., 518(C):363-372.

Roberts, L. Hug, S. J. Voegelin, A., Dittmar, J., Kretzschmar, R.,
Wehrli, B., Saha, G.C., Badruzzaman, A.B.M. \& Ali, M.A. (2011): Arsenic dynamics in porewater of an intermittently irrigated paddy field in Bangladesh. Environ. Sci. Technol., 45(3):971-976.

Roy, D., Mani, V., Kaur, H. \& Kewalramani, N. (2008): Status of Arsenic and Mercury in Different Sources of Water in Haryana. Anim. Nutr. Feed Technol., 8(2):273-278.

Rubin, E.S. (1999). Toxic releases from power plants. Environ. Sci. Technol., 33:3062-3067.

Sanyal, S.K. \& Nasar, S.K.T. (2002): Analysis and Practice, in Water Resources Engineering for Disaster Mitigation. Pub. by: New Age International (P) Limited, New Delhi, pp. 216-222.

Schneider, J.F., Johnson, D.O., Stoll, N., Thurow, K. \& Thurow, K., (1999): Portable X-ray fluorescence spectrometry characterization of a German military site for arsenic contamination in soil. J. Field Anal. Chem., 4:12-17.

Sidhu, S.S., Brar, J.S., Biswas, A., Banger, K. \& Saroa, G.S. (2012): Arsenic Contamination in Soil-Water-Plant (Rice, Oryza sativa L.) Continuum in Central and Sub-mountainous Punjab, India. Bull. Environ. Contam. Toxicol., 89(5):1046-1050.

Sierra, J., Montserrat, G., Marti, E., Garau, M.A. \& Cruañas, R. (2000): Contamination levels in the soils affected by the flood from Aznalcollar, Spain. Soil Sedim. Contam., 9:(4):311-329.

Singh, V., Brar, M.S., Sharma, P. \& Malhi. S.S. (2010): Arsenic in Water, Soil, and Rice Plants in the Indo-Gangetic Plains of Northwestern India. Commun. Soil Sci. Plan Anal., 41(11):1350-1360.

Spanu, A., Daga, L., Orlandoni, A. M. \& Sanna, G. (2012): The Role of Irrigation Techniques in Arsenic Bioaccumulation in Rice (Oryza sativa L.). Environ. Sci. Technol., 46(15):8333-8340.

Srivastava, P.K., Singh, M., Gupta, M., Singh, N., NathKharwar, R., Tripathi, R.D. \& Nautiyal, C.S. (2015): Mapping of arsenic pollution with reference to paddy cultivation in the middle Indo-Gangetic Plains.Environ Monit Assess.,187(4):198.

Tokunaga, S. \& Hakuta, T. (2002): Acid washing and stabilization of an artificial arsenic-contaminated soil. Chemospehere, 46(1):31-38.

Uchino, T., Roychowdhury, T., Ando, M. \& Tokunaga, H. (2006): Intake of arsenic from water, food composites and excretion through urine, hair from a studied population in West Bengal, India. Food Chem. Toxicol., 44(4):455-461.

WHO (2011): Arsenic in drinking water-background document for development of WHO guidelines for drinking-water quality. http://www.who.int/water_sanitation_health/dwq/chemic als/arsenic.pdf

Williams, P.N., Villada, A., Deacon, C., Raab, A., Figuerola, J., Green, A.J., Feldmann, J. \& Meharg, A.A. (2007): Greatly enhanced arsenic shoot assimilation in rice leads to elevated grain levels compared to wheat and barley. Environ. Sci. Technol., 41(19):6854-6859.

Wong, H.K.T., Gauthier, A., \& Nriagu, J.O. (Mar 1999). Dispersion and toxicity of metals from abandoned gold mine tailings at Goldenville, Nova Scotia, Canada. Sci. Total Environ., 228(1):35-47.

Zhao, F.J., McGrath, S.P. \& Meharg, A.A. (2010): Arsenic as food chain contaminant: mechanism of plant uptake and metabolism and mitigation strategies. Annu. Rev. Plant Biol., 61:535-559. 